Feature Article

\title{
Pangolins (Manis crassicaudata) in Sri Lanka: A Review of Current Knowledge, Threats and Research Priorities
}

\author{
P.K.P. Perera*, K.V.D.H.R. Karawita and M.G.T. Pabasara \\ Department of Forestry and Environmental Science, University of Sri Jayewardenepura, \\ Nugegoda, Sri Lanka
}

\begin{abstract}
The Indian Pangolin (Manis crassicaudata) is arguably the least studied species of all Asiatic pangolin species and, is the solitary pangolin species recorded in Sri Lanka. Growing concerns over their population decline due to poaching and trading has triggered a move to uplift Indian Pangolin to Appendix I of the Convention on International Trade in Endangered Species of Wild Fauna and Flora (CITES). However, lack of reliable scientific information on the behavior, ecology and threats for the survival of Indian Pangolin remains a major limitation in conservation of the species. This narrative review discusses the current knowledge on Indian Pangolin with special reference to Sri Lanka, and identifies key research priorities for better conservation planning of the species.
\end{abstract}

Key words: Indian Pangolin, trading, poaching, conservation, ecology, behaviour

\section{Introduction}

Pangolins are unique mammals of the Family Manidae (Gray, 1821) in the Order Pholidota (Weber, 1904). Pangolins are also known as "scaly anteaters" because of the presence of keratinized plate-like protective scales covering most part of their bodies, and their highly specialized diet which predominantly consist of ants and termites. Eight different pangolin species have been described from Afro-tropical and Indo-Malayan regions of the world (Gaubert and Antunes, 2005). Based on the geographic distribution, pangolin species are broadly categorized into two groups; African pangolins and Asian pangolins. Four pangolin species are restricted to Asia; Chinese pangolin (Manis pentadactyla), Sunda pangolin (Manis javanica), Indian pangolin (Manis crassicaudata) and Philippine pangolin (Manis culionensis). Pangolins are at a greater conservation risk due to excessive hunting and poaching, and they may be the most illegally trafficked group of mammals in the world (Challender, 2013; Aisher, 2016) . Out of the four Asiatic pangolin species, M. pentadactyla and $M$. javanica have been categorized as Critically Endangered, while the other two Asiatic pangolin species have been listed as Endangered by the International Union for Conservation of Nature (IUCN, 2016). All eight pangolin species have been recently included in the Appendix I of the Convention on International Trade in Endangered Species of Wild Fauna and Flora, where international trading for commercial purposes of listed species is strictly prohibited (CITES, 2016).

\section{About the Indian Pangolin}

Among all Asian pangolin species, Indian pangolin may be the least studied species (Mahmood et al., 2014). It is the only pangolin species recorded in Sri Lanka. In Sinhalese it is commonly called 'Aeya' or 'Kaballewa', and in Tamil it is referred to as 'Alangu'. Indian pangolin has been considered as an iconic species with a cultural significance in Sri Lankan tradition and history.

*Correspondence: priyan@sjp.ac.lk

Tel: +94-112758411, Fax: +94 112803470

ISSN 2235-9370 Print / ISSN 2235-9362 Online @2017 University of Sri Jayewardenepura 


\section{Morphology and behavior}

Also known as the thick-tailed pangolin, $M$. crassicaudata is a medium-sized mammal that has an elongated tapering body covered with large overlapping scales. Scales are absent on ventral side of the body, head, inner surfaces of limbs and foot pads (Heath, 1995). These moveable scales are shedded periodically. The number and the pattern of scales may show intraspecific variations (Heath, 1995; Kaspal, 2010). According to published descriptions, the number of rows of body scales can vary from 11 to 18 (Kaspal, 2010; Prater, 1980). The colour of scales varies from shades of brown to yellow, and often depends on the colour of the soil associated with the habitat of the animal. The terminal scale on the ventral side of the prehensile tail of the Indian pangolin is a distinct feature to differentiate them from other pangolin species (Heath, 1995). Unlike most mammals, hair is virtually absent on dorsal surface of pangolins except some thick, short hair present in between scales. However, thin, long, light coloured hairs are present on the bare parts underneath (Kotagama and Goonatilake, 2013).

Indian pangolins are largely fossorial, but they are swift climbers as well. While walking on the ground, the tail and trunk are kept parallel to the ground with the back slightly arched (Figure 1A). The hind legs are used to stand upright and search or sniff the surrounding air to detect prey (Israel et al., 1987). Indian pangolin's forelegs are specifically adapted for burrowing and digging. The three central claws are long and slightly curved (Figure 1C). When climbing, forelimbs are used to tightly grip the tree, while the hind limbs are used to push the body upwards, and the tail helps to balance when arboreal (Prater, 1980). The Indian pangolin can quickly roll itself into a compact ball in self-defense, exposing only its scales to a predator (Figure 1B), and hissing loudly to scare off the predator. It can secrete a fluid with an irritating odor from their anal glands when disturbed or distressed by predators or humans (Roberts, 1997).

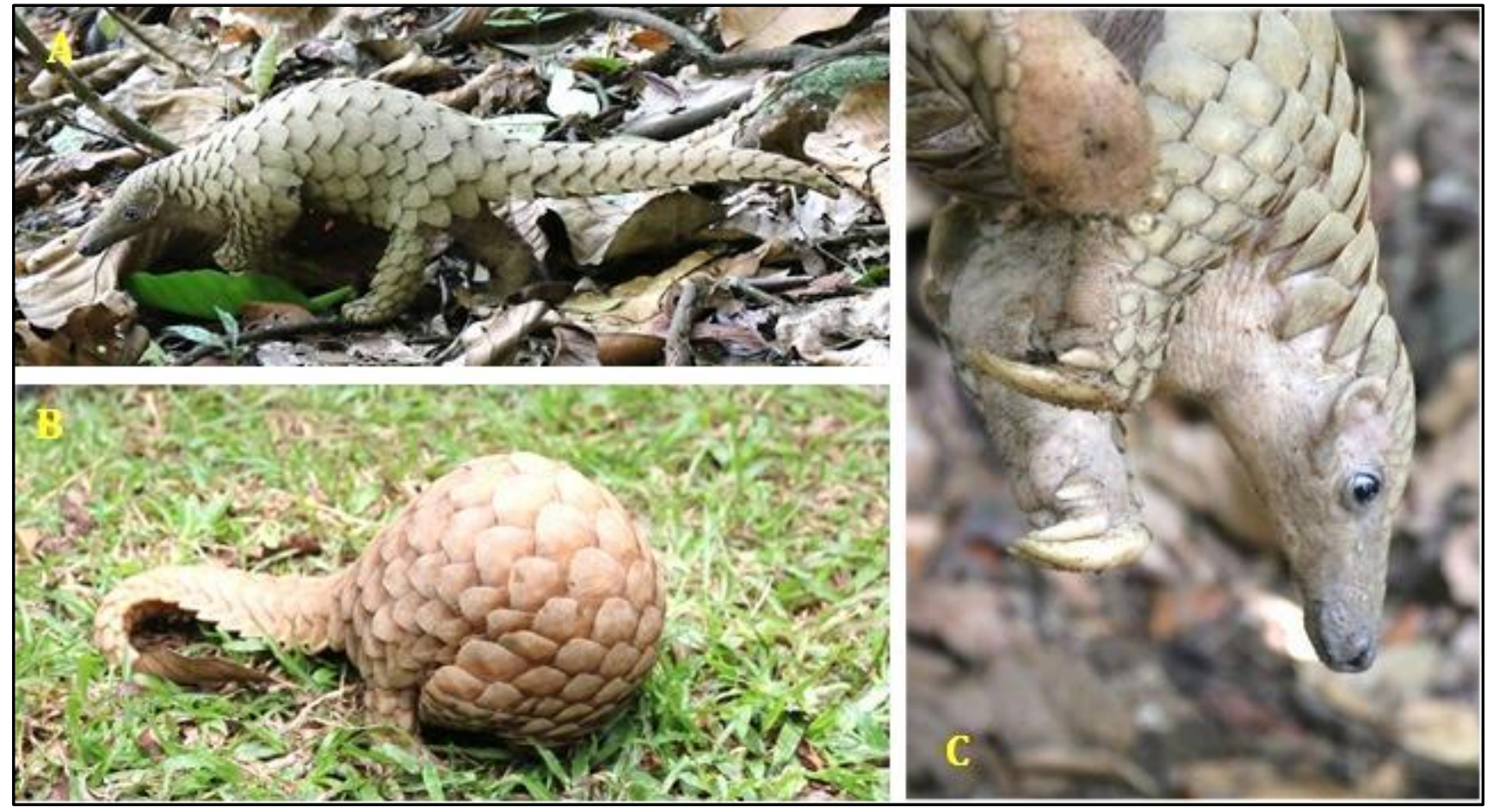

Figure 1: The Indian Pangolin (A) Adult male walking on the ground (B) A rolled-up Pangolin showing its defensive behaviour (C) Forelimbs of Pangolin with sharp claws

Indian pangolin is myrmecophagous and thus has unique anatomical adaptations to pray on ants and termites (Yang et al., 2007). These adaptations include a conical-shaped head, absence of teeth, a long sticky flexible tongue and robust forelimbs with enlarged claws for procuring and eating ants and termites 
(Swart et al., 1999, Botha and Gaudin, 2007, Atkins, 2004). Morpho-anatomical studies of Indian pangolin have revealed that the length of the tongue of an adult Indian pangolin can be up to $37 \%$ of the body length, and the average length of the tongue of an adult is about $42.5 \mathrm{~cm}$ (Chakkaravarthy, 2012; Irshad et al., 2016). Indian pangolins have poor eyesight, but they have a highly-developed olfactory senses to detect their prey as well as predators (Israel et al., 1987).

The Indian pangolins are nocturnal animals and they sleep during the day in burrows, hollows or dens. Their activities are mostly recorded in the night (Dickman and Richer, 2001). They are solitary mammals and seldom seen in groups. Males are substantially larger than females at the same maturity. Their breeding ecology and behavior is poorly understood. Indian pangolins usually give birth to one offspring and rarely the litter size can be up to two (Prater, 1980; Israel et al., 1987). The female carries its newborn on the dorsal base of the tail. The mother coils her body, taking the cub into the center of the coil when she feels the cub is insecure (Heath, 1995).

\section{Distribution}

Indian pangolin naturally occurs in larger part of South Asia (Figure 2) and its geographic range extends from eastern Pakistan through much of India (excluding northeastern parts), Bangladesh, Sri Lanka, Nepal, and up to Myanmar (Wilson and Reeder, 2005; Mishra and Panda, 2012). Some Indian pangolin populations have also been recorded from southwest China (Roberts and Vielliard, 1971). The Indian pangolin is known to inhabit various habitat types. In eastern Pakistan, the species have been recorded from arid grasslands, deserts and barren hilly areas up to 2300 feet above mean sea level (Mahmood et al., 2012; Mahmood et al., 2014). In India, it shows a wide distribution from south of India to southern lower hills of the Himalayas, covering an array of natural and manmade habitats including tropical rain forests, subtropical thorn forests, deciduous forests, open scrub lands, grasslands, cultivated lands and in association with human settlements (Chakkaravarthy, 2012). In Nepal, the species has been recorded particularly from lowlands to the south and west of the country (Baillie et al., 2014). Indian pangolin populations in Bangladesh, China and Myanmar may be very small (Khan, 1985) or possibly extinct (Baillie et al., 2014).

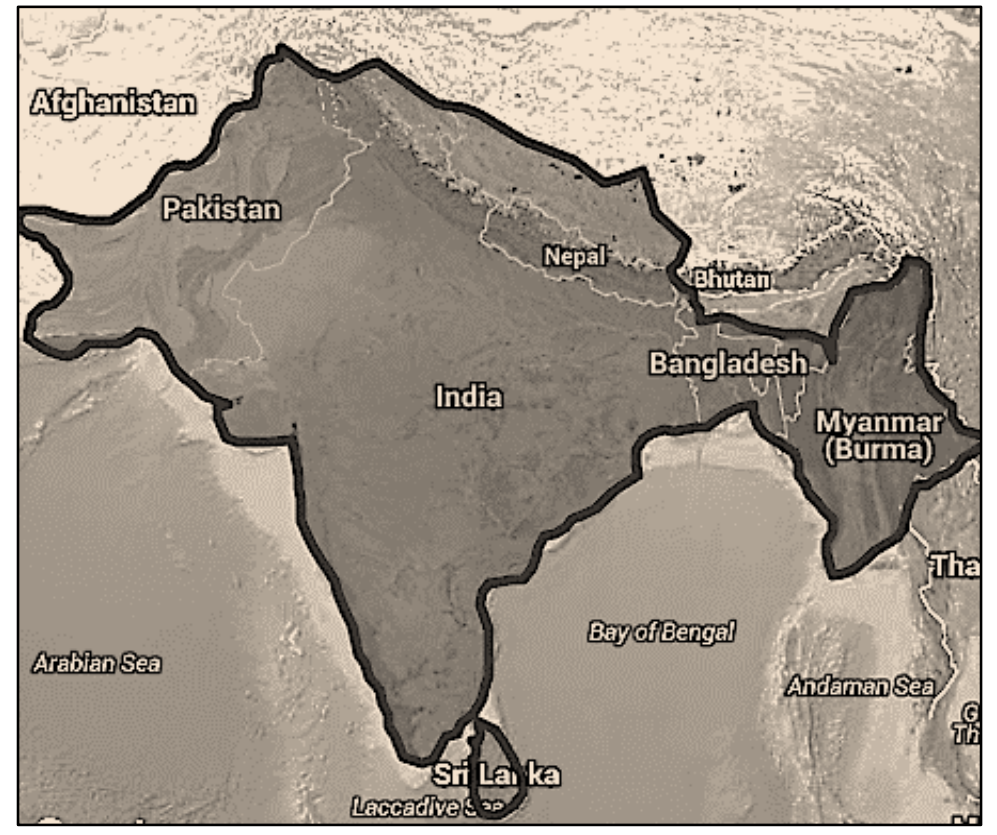

Figure 2: Distribution of the Indian Pangolin - M. crassicaudata

In Sri Lanka, M. crassicaudata is the solitary species belonging to Order Pholidota and it has been recorded from throughout the lowlands up to $1,100 \mathrm{~m}$ above mean sea level with their distribution often 
coinciding with the range of termites (Phillips, 1981). They are of variable abundance in Sri Lanka, with few known locations in both wet and dry zones of the country where pangolins are rather frequently encountered or regularly caught by locals (Pabasara et al., 2015; Karawita et al., 2016). However, no records of the abundance and population numbers are available, and the species is rarely observed due to its secretive, solitary, and nocturnal habits.

\section{Current Knowledge on the Ecology of Indian Pangolins}

Owing to its nocturnal, illusive behavior, the autecology of Indian pangolin remains poorly understood compared to other Asiatic pangolin species (Mahmood et al., 2014). Limited studies in literature have investigated the autecology of Indian pangolins, and a review of current knowledge on the ecology of Indian pangolins is provided herein.

\section{Habitat characterization and preferences}

The Indian pangolin occupies a variety of habitats in its geographical range, and an understanding of its habitat characteristics, habitat preferences, and habitat utilization patterns in different environments is vital for conservation planning of the species. Published ecological studies suggest that the Indian pangolin is capable of adapting to different environments across it's rang. Habitat features such as tree species composition, vegetation cover and geological features (such as presence rock boulders, water sources, and soil characteristics) are important parameters worth considering in habitat characterization (Wu et al., 2003; Mahmood et al., 2014; Pabasara et al., 2015).

The Indian pangolin inhabits different types of tropical forests including wet evergreen forests, moist forests, dry deciduous, thorn and scrub forests, and grasslands up to mid-elevations (Chakkaravarthy, 2012). It is also recorded from degraded wastelands and agricultural lands near human habitations. A study on the habitat preference of Indian pangolins in open barren areas of Potohar Plateau, North-eastern Pakistan reported that pangolin barrows tend to be specifically associated with certain tree or shrub species such as Ziziphus mauritiana, Acacia nilotica, and Zizyphus nummularia (Mahmood et al., 2014). In a comparative study of four habitat types (i.e. Secondary natural forest, Pine-dominated forest, Rubber plantations and Tea-dominated home gardens) associated with a tropical lowland wet evergreen rainforest in southwest Sri Lanka, Pabasara et al. (2015) observed that evidences for the presence of pangolins is highest in Pine-dominated forest. This observation was explained by the greater abundance of prey i.e. termites and ants in Pine-dominated forest where dead and decaying wood logs were more abundant. The same study found that medium slope, low undergrowth, dense canopy closure and presence of rock boulders as the most common habitat features associated with pangolin burrows.

A recent study by Mahmood et al. (2013) suggests that the Indian pangolin digs two types of burrows; living burrows and feeding burrows. Parameters such as barrow depth and diameter as well as the presence of remains of prey items and presence of fecal matter are considered as important signs in distinguishing the two types of pangolin barrows (Irshad et al., 2015). During the day time, pangolins sleep curled inside a "living burrow", which may have several outlets sealed with loose earth (Prater, 1980). Burrows are usually made under large rock boulders or sometimes in tree bases. The depth of the burrow varies depending on the soil type; 1.5 to $2 \mathrm{~m}$ in rocky soils, and up to $5 \mathrm{~m}$ or more in loose soil (Prater, 1965). By comparing the total number of inactive and active living burrows, Mahmood et al. (2013) concluded that the Indian pangolin usually abandons its living burrow after a few months of use, and digs a new one probably within its home range which often overlaps with the distribution and abundance of its pray. Re-occupying an older living burrow is also possible within the same year (Mahmood et al., 2013). Feeding burrows in contrast, are significantly lesser in depth (often less than $1 \mathrm{~m}$ ) and have smaller openings compared to living burrows (Mahmood et al., 2013, Pabasara et al., 2015). 


\section{Feeding ecology}

For the purposes of this review, feeding ecology is defined as the processes which determine general diet of the species including prey selection. When describing the feeding ecology of Indian pangolins, it is essential to have an assessment of their diet. This may be achieved by analysing prey species and remains found in or around feeding burrows, analysis of stomach contents or analysing the undigested prey remains in faeces. An investigation conducted using fecal analysis of Indian pangolins in four districts of Potohar Plateau, Pakistan by Irshad et al. (2015) found that ants (Camponotus confusion, Camponotus compresses) are the major prey of Indian pangolin in the studied habitat while termites (Odontotermis obesus), bugs, wood fibers and grasses constituted other major components of the diet. This study further identified clay and soil particles as the most voluminous components of fecal samples, accounting for about $48 \%$ to $62 \%$ of the fecal matter respectively. The passive intake of soil and clay particles is considered to aid in the mechanical digestion process inside the stomach where there is virtually no mechanical digestion takes place in the oral cavity due to the absence of teeth.

Though considered as myrmecophagous, Indian pangolins may oppertunistically feed on beetles, cockroaches, magotts and larvae of insects as revealed by gut content analysis studies (Hutton, 1949; Lekagul and Mcneely, 1977; Heath, 1995; Mahmood et al., 2013) and according to local knowledge (Pabasara et al., 2015; Karawita et al., 2016). The eggs of the ants are more preferred by the Indian pangolins over ants, and they prefer feeding on prey found by burrowing rather than the prey species fond on the soil or rock surfaces (Heath, 1995). Some observations report that captive Indian pangolins refused feeding on red ants and termites, and showed a specific liking to feed on the black ants (Mohapatra and Panda, 2014b).

Indian pangolin has highly specialized feeding habits. They feed mainly on eggs, nymphs and adults of termites and ants by digging the termite or ant nests (Mohapatra and Panda, 2014b). Before digging the termite or ant nests, they use their highly developed olfactory organs to rapidly sniff around the area to determine the most suitable place of the nest to attack. When digging deep into or under mounds, they move out backwards to expel soil with their forefeet. Hind legs are used to throw loose soil backwards. The animal feed rapidly by extending the long protrusible tongue into the galleries of nests (Payne and Francis, 1998 ). The rostral part of the tongue is quickly inserted and withdrawn to capture prey. This movement is also used in drinking (Mohapatra and Panda, 2014a). Due to the absence of teeth, food is directly taken into the stomach and subjected to mechanical grinding.

\section{Abundance, population estimates and trends}

There is insufficient information available on population levels of all Asiatic pangolin species (Baillie et al., 2014). Only a handful of studies have attempted to estimate the abundance and population size of Indian pangolins. For instance, Mahmood et al. (2014) estimated the population size of Indian pangolins in the district of Chakwal in Potohar Plateau, Pakistan by counting the active living burrows of Indian pangolins along established transects. Their study reported a population density of 0.067 individuals per $\mathrm{km}^{2}$. A survey in the same study area has further documented a rapid population decline due to illegal mass killing of Indian pangolins for their flesh and scales (Mahmood et al., 2012).

In contrast, a study conducted by Pabasara (2016) to assess the abundance of Indian pangolin in Yagirala Forest Reserve; an isolated patch of Tropical Lowland Rainforest in South-West Sri Lanka reported a population density of 5.69 individuals per $\mathrm{km}^{2}$. This study employed camera trapping techniques, and the population estimate was based on the model described by Rowcliffe et al. (2008). The population density of Indian pangolins reported by Pabasara (2016) is considerably higher than Mahmood et al. (2014)'s estimate. This discrepancy may be due to the differences in habitats where tropical rainforests being more diverse and abundant in terms of prey species of Indian pangolin, or may be due to the different methodological approaches used. Pabasara (2016) also used photographic records to estimate the abundance of Indian pangolins with "Occurrence Index" described in Shek et al (2007). A survey of 
local hunters and the community in Yagirala Forest surroundings by Karawita et al. (2016) has further reported concerns over alarming exploitation levels of Indian pangolins, potentially leading to decline of the local population of Indian pangolins. Although several other published works indicate a negative trend in the population levels of Indian pangolins across its geographical range (Baillie et al., 2015; Challender et al., 2015), lack of scientific studies on population estimates continues to be a significant hindrance in assessing its conservation needs.

\section{Husbandry and behavior in captivity}

The history of attempts on captive management and husbandry of Indian pangolins dates back to 1892 (Sanyal, 1892), yet there is a lack of scientific knowledge on the best practices of captive management of Indian pangolins. Numerous attempts have been made to raise India pangolins in captivity, particularly in zoos. According to Yang et al. (2007), rearing Indian pangolin in captivity have been attempted between years 1941 to 1970 in Zoos of Jaipur, Simba, Calcutta, Ahmedabad and Madras in India, Dehiwala Zoo in Colombo, Sri Lanka, Antwerp Zoo in Belgium, Wilhelma Zoo in Stuttgart, Germany, Prague Zoological Garden in Prague, the Czech Republic, zoos of Detroit, Pittsburgh, St. Louis, Chicago Brookfield, Miami Crandon Park, Oklahoma, Mesker Park Zoo in Indiana, and Milwaukee Zoo in Wisconsin in the US. However, most of such attempts have failed to maintain the animals for longer periods. Dietary problems and stress have been often cited as the major causes of mortality of Indian pangolins under captive conditions (Yang et al., 2007; Pattnaik, 2008).

For instance, a captive rearing attempt of Indian pangolin has been recorded from Oklahoma City Zoo, USA in 1965 (Ogilvie and Bridgwater, 1967). A pair of Indian pangolins captured from Gadani - an area closer to Karachi, Pakistan was shipped to the Oklahoma City Zoo. The animals have been fed with a diet consisting of horse meat, dog feed, evaporated canned milk, eggs, a mixture of vitamin A, B, C, D, and $\mathrm{E}$ with parts of decaying logs to lure them to feed on the captive diet. Animals have been housed in a room measuring $2.4 \mathrm{~m} \times 3.0 \mathrm{~m}$ with the floor covered with wheat straw or hay. According to the notes of Ogilvie and Bridgwater (1967), pangolins had shown a behavior of deliberate addition of litter to the body coil before they sleep on the floor. The male pangolin became weaker due to rejection of food and was suffering from severe infection beneath the dorsal scales. The male pangolin did not survive even a month in captivity. The postmortem revealed that the larynx of the pangolin was clogged with a heavy mass of food and the death possibly caused due to suffocation. The female individual gave birth to one male cub within two months in captivity. Mother cared the newborn by coiling around the cub. The newborn cub also died three days after the birth due to starvation. Several other artificial diets have been used or suggested by various researchers in rearing Indian pangolins in captivity (Ramakantha, 1992, Yadav, 1973). Yet, the species may find it difficult to adapt to an artificial diet and even reject its regular live prey probably due to stress when kept in captive environments. According to published reports, the mortality rate of Indian pangolins is $67-71 \%$ within the first year in captivity with only $11.5 \%$ living more than 2.5 years (Lal-Mohan, 1997; Chakkaravarthy, 2012).

The Pangolin Conservation Breeding Center (PCBC) of Nandankanan Biological Park in India has been successful in husbandry and captive breeding of the Indian pangolins, and has been in operation since 2008 (Chakkaravarthy, 2012; Mohapatra and Panda, 2014a). At PCBC, pangolins are individually housed in $4.8 \times 4.2 \times 3.0 \mathrm{~m}$ enclosures with $0.5 \mathrm{~m}$ deep red laterite soil provided as substrate, and wooden logs and poles provided as enrichment materials. The enclosure design further consists of reinforced concrete walls on all four sides up to a height of $1.0 \mathrm{~m}$ and chain-link mesh netting provided on all four sides above the level of concrete base to facilitate proper ventilation and natural sunlight. Considering the success of the program, the enclosure design, daily husbandry routine, diet and veterinary care procedures used at PCBC may provide useful guidelines for future captive breeding efforts.

Captive behaviors of Indian pangolin have been also investigated at the PCBC using CCTV (Close circuit television) camera systems (Mohapatra and Panda, 2014a). Some preliminary observations 
revealed that captive Indian pangolins display the natural pattern of nocturnal activity with a peak activity period between 20:00 to 21:00 hours, while an intermittent level of activity has been recorded between 17:00-05:00 hours. During the period where they are active, a greater proportion of time is spent on walking in the enclosure while some individuals exhibited pacing behaviour in the shape of " 8 " or "O". According to Mohapatra and Panda (2014a), Indian pangolins prefer wet soil substrates for digging, and also seek shelter under hollow wooden logs placed inside the enclosure.

\section{Threats and Conservation}

The Indian pangolin is timid, inoffensive and rather a slow mover. It predominantly relies on 'rolling-up' mechanism for defense, and thus can easily fall prey to poachers. Increased market demand for pangolin meat and scales has shifted hunting for local consumption to international trade, which in turn has intensified the exploitation of Indian pangolin populations.

\section{Traditional uses}

Indian pangolin has been traditionally hunted by different tribal communities throughout its geographical range for variety of purposes; especially for ethno-medical uses. For instance, In India, some ethnic groups believe that scales and claws of Indian pangolin possess antiseptic properties, and thus use pangolin claws to pierce boils or skin abscess, and ointments made of pangolin scales to heal wounds and inflammations (Mohapatra et al., 2015). Bile of the Indian pangolins is used by some communities in Arunachal Pradesh of India to cure the splenomegaly (Chinlampianga et al., 2013) while some forestdwelling tribes in Orissa, India are known to wear rings made of Indian pangolin scales as a remedy for piles/haemorrhoids (Mishra and Rout, 2009). Indian pangolin scales are also believed to have nematocidal properties (Betlu, 2013).

In Nepal, some communities consider pangolin flesh as a remedy for asthma and rheumatic fever, while oil extracted from pangolin scales is used to treat bone and muscle disorders (Kaspal, 2010). Pangolin scales are also used by tribal ethno-medical practitioners in treating infertility in women (Katuwal et al., 2013). Cultural and mythical beliefs of certain tribal communities have also caused Indian pangolin populations to decline over the years in Nepal. For instance, using pangolin scales in children's' jewelries is believed to protect them from evil spirits, and wearing pangolin scales is believed to bring luck (Katuwal et al., 2013). In Pakistan, traditional and ethno-medical practitioners also value pangolin body parts as ingredients for variety of traditional medicines (Roberts, 1997).

Unlike in other countries where Indian pangolin is native, evidences for using pangolin body parts for traditional Ayurveda medicine are scarce or non-existent in Sri Lanka (Karawita et al., 2016). Instead, it has been long consumed as a bush-meat by local communities. For instance, ethno-archaeological studies on the subsistence patterns of the indigenous "vedda" community of Sri Lankan has revealed that the flesh of Indian pangolins have been traditionally consumed by "vedda" community, and in hunting they have used smoke to drive pangolins out of the burrows (Chandraratne, 2016). Furthermore, bone parts of the Indian pangolins have also been found from Mesolithic explorations in "Beli-Lena"; a prehistoric cave in Sri Lanka (Kajale, 2014).

\section{Local and international trade}

Indian pangolin at present is under severe hunting pressure due to local consumption and rising demand for its scales and meat in East Asian markets, especially the Chines markets (Baillie et al., 2015; Challender, 2011). According to expert observations, the virtual extirpation of $M$. pentadactyla and $M$. javanica in East Asia is the major factor that drives the high demand for $M$. crassicaudata in international markets at present (Baillie et al., 2004; Challender, 2013; Mohapatra et al., 2015). The Indian pangolin populations in India and Pakistan have been over-exploited for international trade with most smuggled specimens and parts ending up in Chines and Myanmar markets (Baillie et al., 2015). According to a 
recent survey by Mahmood et al. (2012), 118 Indian pangolins have been killed for flesh and scales during the period from January 2011 to May 2012 in Potohar region of Pakistan alone, while an estimated 1,690 specimens of Indian pangolin have been confiscated from illegal trade between 2009 and 2014 in India (Mohapatra et al., 2015).

In Sri Lanka, pangolin flesh is considered a delicacy by local hunters. As a result of excessive hunting, pangolins have been almost eliminated in areas where they stray into contact with people. Unlike in other countries of the region, reported cases international trade of pangolin scales or specimens is very limited (Karawita et al., 2016). Hence, the major threat for their survival comes from local hunters. Since year 2000 to June 2017, only three attempted cases of smuggling pangolin scales from Sri Lanka have been reported by the Sri Lanka Customs; in 2012 and 2016 (Figure 3). In all occasions, the offenders were trying to smuggle pangolin scales to India. However, these recent confiscations cannot be considered as isolated incidents, and may hint possible international trading of pangolin scales from the country in a much larger magnitude through multiple channels.

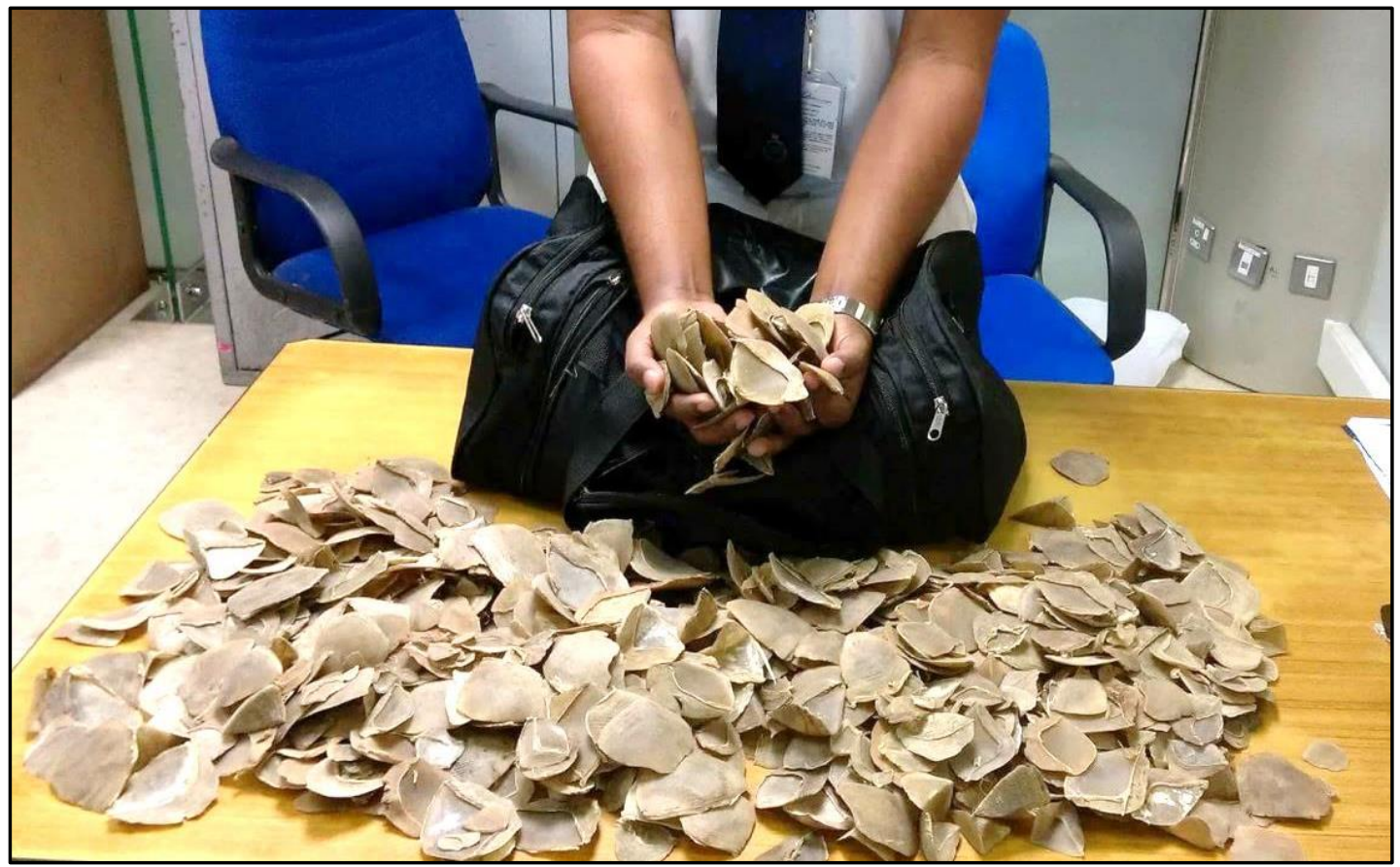

Figure 3: Confiscated pangolin scales by Biodiversity, Cultural and National Heritage Protection Division of Sri Lanka Customs at the Bandaranayake International Airport, Sri Lanka (Photograph: Sri Lanka Customs, 2017)

Preliminary investigations by Karawita et al. (2016) revealed the existence of possible niche local markets for pangolin meat where some restaurants catering predominantly for foreigners, have reportedly paid lucrative money to local hunters in supply of pangolin meat. Nonetheless, such claims need further validation through in-depth studies. Apart from poaching and hunting, rapid loss and deterioration of habitats, agricultural expansions, ad-hoc use of pesticides and road-kills are also cited as other threats for the survival of Indian pangolin (Chakkaravarthy, 2012; Karawita et al., 2016).

\section{Conservation}

Populations levels of Indian pangolin is believed to have a declining trend in all countries where it naturally occurs and, according to IUCN projections, populations of this species will fall at least by $50 \%$ in the next 20 years, especially given the present high rate of exploitation (Mahmood et al., 2012; Baillie et al., 2014). Their naturally low birth rate with female pangolins producing mostly one offspring a year has also contributed to the negative population trend (Zhou et al., 2014). Recognizing the high level of 
risk the species is faced with, M. crassicaudata has been listed as an Endangered (EN) species by the IUCN (Baillie et al., 2014). Enabling greater protection from international trading, the species has been further transferred from Appendix II to Appendix I of the Convention on International Trade in Endangered Species of Wild Fauna and Flora (CITES).

The Indian pangolin is listed under 'Near Threatened' (NT) category of the National Red List of Sri Lanka (Weerakoon, 2012). It is also included in the schedule II of the Flora and Fauna Protection Ordinance (Amendment) Act No. 22 of 2009 of Sri Lanka. The schedule II includes mammals and reptiles that are strictly protected by law. The Department of Wildlife Conservation of Sri Lanka has further included Indian pangolin among country's five 'most concerned' animals (DWC, 2016). Despite such strict protective legal measures, Indian pangolins continue to be illegally captured and killed for local consumption in various parts of Sri Lanka.

\section{Future Research Priorities for Sri Lanka}

As highlighted in this review, only a few studies have been carried out on wild populations of Indian pangolins across its range (Table 1). These are localized studies carried out in few selected habitats or environments, and thus having location-specific information. Given the wide variety of habitats that Indian pangolins occupy, published data on population sizes and distribution are insufficient to enable an accurate assessment of their conservation needs. Although habitat preferences, feeding ecology and behaviours of Indian pangolin have been investigated elsewhere (Table 1), there is still a dearth of information on the autecology of the species. In Sri Lanka, preliminary investigations on selected aspects of autecology of the Indian pangolin have been attempted in a tropical lowland forest habitat (Pabasara, 2016). Other than that, no published studies on the ecology and population levels of $M$. crassicaudata is available in Sri Lanka. Considering their high vulnerability and deficiency of population data, the Indian pangolin should receive more conservation priority in Sri Lanka. Hence studies on population abundance and autecology of Indian pangolin are of greater importance in the Sri Lankan context.

One of the major impediments in studying wild pangolins has been the difficulty in locating them. As such, standard ecological census and monitoring techniques may not be well suited for the detection and surveying of pangolins (Newton et al., 2008). Determining absolute densities of animals is complex and often controversial. For many species, however, direct counts are impractical and researchers may need to rely on indirect signs, such as tracks, scats or den sites (Wilson and Delahay, 2001). Radio telemetry techniques are widely used in studying the ecology of wild animals as a cost-efficient method compared to GPS tracking methods. Such methods allow easy observation of the activity cycle, habitat preference, feeding grounds and resting places of the pangolins (Norman, 2009). The potential of radiotracking wild-caught pangolins to monitor home-range size and habitat utilization has been demonstrated by previous works (Heath and Coulson, 1997; Lim and Ng, 2008; Richer et al., 1997). In these studies, radio transmitters were tagged to the dorsal scales closer to the base of the tail of pangolins to minimize disturbances to their usual behaviors in the wild. For instance, Lim and $\mathrm{Ng}$ (2008) used a combination of radio-telemetry and infrared-triggered camera traps to study the home range, activity cycle and natal den usage of Manis javanica. However, these radio-tracking studies have been conducted in areas with high pangolin densities. As Indian pangolins are rapidly becoming nowhere common, development of field detection and monitoring methodologies applicable to habitats with low population densities will be of more relevance in future research. Use of mixed methodologies may also be helpful in population studies of highly illusive species such as Indian pangolins. For instance, Newton et al. (2008) used local hunters' knowledge to understand the distribution and abundance of pangolins (Manis pentadactyla and $M$. javanica) in Vietnam. Camera trapping techniques have also been used to determine the distribution and abundance of pangolins (Pabasara, 2016). In some cases, baits have been used to attract pangolins towards the camera trap (Marler, 2016). 
Table 1: Recent studies on Indian pangolin M. crassicaudata

\begin{tabular}{|c|c|c|c|c|}
\hline Study scope & Recent studies & $\begin{array}{l}\text { Range } \\
\text { Country }\end{array}$ & $\begin{array}{l}\text { Information gaps and } \\
\text { limitations }\end{array}$ & $\begin{array}{l}\text { Research priority } \\
\text { for Sri Lanka }\end{array}$ \\
\hline \multirow[t]{3}{*}{$\begin{array}{l}\text { Ecology, behavior } \\
\text { and population } \\
\text { distribution }\end{array}$} & $\begin{array}{l}\text { Mahmood et al (2013); Mahmood et } \\
\text { al (2014); Irshad, et al (2015); } \\
\text { Mahmood et al. (2015); Mahmood et } \\
\text { al (2016); Akrim et al (2017) }\end{array}$ & Pakistan & $\begin{array}{l}\text { Limited geographical } \\
\text { coverage, Highly localized } \\
\text { studies under few selected } \\
\text { habitats or environments }\end{array}$ & $\begin{array}{l}\text { Limited and } \\
\text { incomplete } \\
\text { information } \\
\text { available }\end{array}$ \\
\hline & Mishra and Panda( 2012) & India & & High priority \\
\hline & Pabasara et al. (2016) & Sri Lanka & & \\
\hline $\begin{array}{l}\text { Trading, poaching } \\
\text { and extraction }\end{array}$ & $\begin{array}{l}\text { Mahmood et al. (2012) } \\
\text { Chakkaravarthy (2012); Mohapatra, et } \\
\text { al (2015); Kumar, et al (2016) }\end{array}$ & $\begin{array}{l}\text { Pakistan } \\
\text { India }\end{array}$ & $\begin{array}{l}\text { Findings are mainly based } \\
\text { on secondary information } \\
\text { and limited primary data } \\
\text { obtained through case } \\
\text { studies }\end{array}$ & $\begin{array}{l}\text { No published } \\
\text { information } \\
\text { available } \\
\text { High Priority }\end{array}$ \\
\hline $\begin{array}{l}\text { Community } \\
\text { perceptions and } \\
\text { awareness on } \\
\text { conservation }\end{array}$ & $\begin{array}{l}\text { Kaspal (2010) } \\
\text { Chakkaravarthy (2012) } \\
\text { Karawita et al (2016) }\end{array}$ & $\begin{array}{l}\text { Nepal } \\
\text { India } \\
\text { Sri Lanka }\end{array}$ & Localized case studies & $\begin{array}{l}\text { Limited and } \\
\text { incomplete } \\
\text { information } \\
\text { available } \\
\text { High Priority }\end{array}$ \\
\hline $\begin{array}{l}\text { Captive behavior, } \\
\text { conservation } \\
\text { breeding and } \\
\text { husbandry }\end{array}$ & $\begin{array}{l}\text { Mohapatra and Panda (2013); } \\
\text { Mohapatra and Panda (2014a); } \\
\text { Mohapatra and Panda (2014b); } \\
\text { Mohapatra, et al (2015) }\end{array}$ & India & $\begin{array}{l}\text { Studies conducted under } \\
\text { variable captive } \\
\text { environments with most } \\
\text { studies reporting limited } \\
\text { success in maintaining } \\
\text { animals in captivity }\end{array}$ & $\begin{array}{l}\text { No published } \\
\text { information } \\
\text { available } \\
\text { Moderate Priority }\end{array}$ \\
\hline $\begin{array}{l}\text { Genetics and } \\
\text { Biochemistry }\end{array}$ & $\begin{array}{l}\text { Mathur and Rathi (1966); } \\
\text { Aswathanarayana (2000); Mohapatra } \\
\text { et al (2014) }\end{array}$ & India & & Low Priority \\
\hline $\begin{array}{l}\text { Anatomy and } \\
\text { morphology }\end{array}$ & Irshad et al. (2016) & Pakistan & & Low priority \\
\hline
\end{tabular}

Another major obstacle in assessing the conservation needs of $M$. crassicaudata in Sri Lanka is the absence of accurate information on hunting, poaching and extraction levels of the species. Published data are mainly based on secondary information and limited primary data obtained through case studies. Records on international trading of pangolins originated from Sri Lanka in the literature are scarce (Challender et al., 2015). Lack of public awareness on the conservation importance of Indian pangolins, and rather low conservation priority given by officials over the years has contributed to the decline of Indian pangolin population in the country. As the major threat for the survival of Indian pangolins is from local communities, an understanding of public perceptions and awareness on pangolin conservation is important. Communities and officials need to be aware of the importance and benefits of pangolin conservation so that they can be effectively involved in conservation measures based on participatory approaches (Chakkaravarthy, 2012). As such, studies directed towards understanding the extraction levels (including possible local and international trading) of pangolins and local community awareness on pangolin conservation in Sri Lanka should be highly prioritized in the research agenda.

Upon the accurate assessment of current threats and population levels, ex-situ conservation programs such as rearing and breeding Indian pangolins in captivity and reintroduction to their natural habitats may be required. Such measures are often expensive and require technical expertise. However, most ex-situ conservation programs of Indian pangolins have not been successful due to the poor understanding of dietary ecology and behavior of the species. As highlighted by previous researchers, comprehensive knowledge on the behaviour of Indian pangolins under captive conditions is vital in 
rearing and management of animals for potential captive breeding programs (Challender, 2009; Mohapatra and Panda, 2014a). CCTV cameras have been successfully used in behavioral observations of captive Indian pangolins (Mohapatra and Panda, 2014a) while infra-red triggered remote camera traps have been employed in captive behavioral studies of other illusive nocturnal mammals (Jayaratna et al., 2015). However, in the Sri Lankan context, such ex-situ conservation measures can be identified as medium to long term actions, and of moderate research priority due to limited scientific information. Instead, in-situ conservation measures should be prioritized.

\section{Conclusion}

Indian pangolin remains as one of the least studied mammals in Sri Lanka and throughout its geographical range to a greater extent. Indian pangolin populations are believed to be rapidly declining. Hunting for local consumption along with habitat loss are the major causes for the decline of Indian pangolin population in Sri Lanka. With the inclusion of Indian pangolin to the Appendix I of the CITES during the $17^{\text {th }}$ meeting of the Conference of the Parties held on October 2016, the interest on conservation of the species has increased. However, the dearth of scientific research on M. crassicaudata in the Sri Lankan context is a major concern in conservation planning of the species. This review identifies three research areas to prioritize in order to generate the essential information to assess conservation needs and in-situ conservation planning of $M$. crassicaudata i.e. (1) Ecology, behavior and population abundance of Indian pangolins (2) Assessment of hunting/poaching/extraction levels of Indian pangolins and (3) Understand the community perceptions and awareness on conservation of Indian pangolins. Research focused on behavior in captivity, conservation breeding and husbandry of Indian pangolins are of moderate research priority as these will predominantly generate information useful for ex-situ conservation measures.

\section{Reference}

Aisher, A. 2016. Scarcity, alterity and value: Decline of the pangolin, the world's most trafficked mammal. Conservation and Society, 14, 317.

Atkins, W. 2004. Pholidota pangolins (manidae). Grzimek's Animal Life Encyclopedia. Volume, 16.

Baillie, J., Challender, D., Kaspal, P., Khatiwada, A., Mohapatra, R. \& Nash, H. 2014. Manis crassicaudata. The IUCN Red List of Threatened Species.

Baillie, J., Challender, D., Kaspal, P., Khatiwada, A., Mohapatra, R. \& Nash, H. 2015. Manis crassicaudata. The IUCN Red List of Threatened Species. Version.

Baillie, J., Hilton-Taylor, C. \& Stuart, S. N. 2004. 2004 iucn red list of threatened species: A global species assessment, Iucn.

Betlu, A. L. S. 2013. Indigenous knowledge of zootherapeutic use among the biate tribe of dima hasao district, assam, northeastern india. Journal of ethnobiology and ethnomedicine, 9, 1.

Botha, J. \& Gaudin, T. 2007. An early pliocene pangolin (mammalia; pholidota) from langebaanweg, south africa. Journal of Vertebrate Paleontology, 27, 484-491.

Chakkaravarthy, Q. A. Research and conservation needs of the indian pangolin (manis crassicaudata). Proceedings of Third Seminar on Small Mammals Conservation Issues, 2012. 50-55.

Challender, D. Asian pangolins: How behavioural research can contribute to their conservation. Workshop on trade and conservation of pangolins native to south and southeast asia, 2009. 95.

Challender, D. 2011. Asian pangolins: Increasing affluence driving hunting pressure. TRAFFIC Bulletin, 23, 92-93.

Challender, D. 2013. The most traded wild mammal-the pangolin-is being eaten to extinction. Iucn. 
Challender, D. W., Harrop, S. R. \& Macmillan, D. C. 2015. Understanding markets to conserve tradethreatened species in cites. Biological Conservation, 187, 249-259.

Chandraratne, R. 2016. Some ethno-archaeological observations on the subsistence strategies of the veddas in sri lanka.

Chinlampianga, M., Singh, R. K. \& Shukla, A. C. 2013. Ethnozoological diversity of northeast india: Empirical learning with traditional knowledge holders of mizoram and arunachal pradesh. Indian Journal of Traditional Knowledge, 12, 18-30.

CITES. 2016. Consideration of proposals for amendmentof appendices $i$ and ii [Online]. Available: https://cites.org/sites/default/files/eng/cop/17/prop/060216/E-CoP17-Prop-11.pdf [Accessed 3 May 2017.

Dickman, C. R. \& Richer, R. A. 2001. Pangolins. . The encyclopedia of mammals, D. W. Macdonald eds. (New York: Facts on File), 800-801.

DWC, 2016. Sri Lanka's Five Most Concerned. Department of Wildlife Conservation,Sri Lanka.

Gaubert, P. \& Antunes, A. 2005. Assessing the taxonomic status of the palawan pangolin manis culionensis (pholidota) using discrete morphological characters. Journal of Mammalogy, 86, 10681074.

Gray, J. E. 1821. On the natural arrangement of vertebrose animals. London medical repository, 15, 296310.

Heath, M. E. 1995. Manis crassicaudata. Mammalian Species Archive, 513, 1-4.

Heath, M. E. \& Coulson, I. M. 1997. Preliminary studies on relocation of cape pangolins manis temminckii. South African Journal of Wildlife Research-24-month delayed open access, 27, 51-56.

Hutton, A. 1949. Notes on the indian pangolin (manis crassicaudata). J. Bombay Nat. Hist. Soc, 48, 805806.

Irshad, N., Mahmood, T., Hussain, R. \& Nadeem, M. S. 2015. Distribution, abundance and diet of the indian pangolin (manis crassicaudata). Animal Biology, 65, 57-71.

Irshad, N., Mahmood, T. \& Nadeem, M. S. 2016. Morpho-anatomical characteristics of indian pangolin (manis crassicaudata) from potohar plateau, pakistan. Mammalia, 80, 103-110.

Israel, S., Grewal, B., Hoefer, H. \& Sinclair, T. 1987. Indian wildlife: Sri lanka, nepal, APA Publications, Prentice Hall.

IUCN. 2016 Red list of threatened species [Online]. Available: www.iucnredlist.org [Accessed 03 May 2017].

Jayaratna, C., Perera, P.K.P. \& Dayawansa, N.P. 2015. A preliminary investigation of the behaviour of rusty spotted cats prionailurus rubiginosus in captivity. Wildlanka 3 (1): 1-11.

Kajale, M. 2014. 15 mesolithic exploitation of wild plants in sri lanka: Archaeobotanical study at the cave site of beli-lena. Foraging and farming: The evolution of plant exploitation, 31, 269.

Karawita, K., Perera, P. \& Pabasara, M. 2016. Indian pangolin (manis crassicaudata) in yagirala forest reserve: Ethnozoology and implications for conservation. Proceedings of $21^{\text {st }}$ International Forestry and Environment Symposium, 2016, Sri Lanka.

Kaspal, P. Saving the pangolins: Ethno zoology and pangolin conservation awareness in human dominated landscapes of nepal. Proceeding of the First One Day National Seminar on Small Mammals Issues, 2010. 43-58.

Katuwal, H. B., Neupane, K. R., Adhikari, D. \& Thapa, S. 2013. Pangolins trade, ethnic importance and its conservation in eastern nepal. Small Mammals Conservation and Research Foundation and WWF-Nepal, Kathmandu, Nepal.

Khan, M. a. R. 1985. Mammals of bangladesh: A field guide, Nazma Reza. 
Kotagama, S. \& De A. Goonatilake, S. 2013. Pictorial pocket guide to the mammals of sri lanka: Revised \& expanded.

Lal-Mohan, R. 1997. Manis crassicaudata of malabar-ecology and status. Zoos ' Print XII (11): 33, 34.

Lekagul, B. \& Mcneely, J. 1977. Mammals of thailand. Association for the conservation of wildlife. Kulusapa, Bangkok.

Lim, N. T. \& Ng, P. K. 2008. Home range, activity cycle and natal den usage of a female sunda pangolin manis javanica (mammalia: Pholidota) in singapore. Endangered Species Research, 4, 233-240.

Mahmood, T., Hussain, R., Irshad, N., Akrim, F. \& Nadeem, M. S. 2012. Illegal mass killing of indian pangolin (manis crassicaudata) in potohar region, pakistan. Pakistan J. Zool, 44, 1457-1461.

Mahmood, T., Irshad, N. \& Hussain, R. 2014. Habitat preference and population estimates of indian pangolin (manis crassicaudata) in district chakwal of potohar plateau, pakistan. Russian journal of ecology, 45, 70-75.

Mahmood, T., Jabeen, K., Hussain, I. \& Kayani, A. R. 2013. Plant species association, burrow characteristics and the diet of the indian pangolin, manis crassicaudata, in the potohar plateau, pakistan. Pakistan Journal of Zoology, 45, 1533-1539.

Marler, P. N. 2016. Camera trapping the palawan pangolin manis culionensis (mammalia: Pholidota: Manidae) in the wild. Journal of Threatened Taxa, 8, 9443-9448.

Mishra, N. \& Rout, S. 2009. Ethno-zoological studies and medicinal values of similipal biosphere reserve, orissa, india. African Journal of Pharmacy and Pharmacology, 5, 6-11.

Mishra, S. \& Panda, S. 2012. Distribution of indian pangolin manis crassicaudata gray (pholidota, manidae) in orissa: A rescue prospective. Small Mammal Mail, 3, 51-53.

Mohapatra, R. K. \& Panda, S. 2014a. Behavioural descriptions of indian pangolins (manis crassicaudata) in captivity. International Journal of Zoology, 2014.

Mohapatra, R. K. \& Panda, S. 2014b. Husbandry, behaviour and conservation breeding of indian pangolin. Folia Zoologica, 63, 73-80.

Mohapatra, R. K., Panda, S., Nair, M. V., Acharjyo, L. N. \& Challender, D. W. 2015. A note on the illegal trade and use of pangolin body parts in india. Traffic Bulletin, 27, 33.

Newton, P., Van Thai, N., Roberton, S. \& Bell, D. 2008. Pangolins in peril: Using local hunters' knowledge to conserve elusive species in vietnam. Endangered Species Research, 6, 41-53.

Norman, T. Ecological research and conservation of sunda pangolin manis javanica in singapore. Workshop on trade and conservation of pangolins native to south and southeast asia, 2009. Citeseer, 90.

Ogilvie, P. \& Bridgwater, D. 1967. Notes on the breeding of an indian pangolin manis crassicaudats at oklahoma zoo. International Zoo Yearbook, 7, 116-118.

Pabasara, G. 2016. Assessment of the abundance and habitat preference of indian pangolin (manis crassicaudata) in yagirala forest reserve; a tropical lowland forest in south-west sri lanka.

Pabasara, M., Perera, P. \& Dayawansa, N. 2015. A preliminary investigation of the habitat selection of indian pangolin (manis crassicaudata) in a tropical lowland forest in south-west sri lanka. Proceedings of $20^{\text {th }}$ International Forestry and Environment Symposium, 2015, Sri Lanka.

Pattnaik, A. 2008. Enclosure design and enrichment key to the successful conservation breeding of indian pangolin (manis crassicaudata) in captivity. Indian Zoo Year Book V: 91, 102.

Payne, J. \& Francis, C. M. 1998 A field guide to the mammals of borneo. The Sabah Society, Kota Kinabalu.

Phillips, W. W. A. 1981. Manual of the mammals of sri lanka, Wildlife and Nature Protection Society of Sri Lanka. 
Prater, S. 1980. The book of indian animals bombay natural history society and oxford university press. Mumbai.

Prater, S. H. 1965. The book of indian animals, Bombay natural history society.

Ramakantha, V. 1992. A note on pangolin in manipur. WII News-letter 7, 19.

Richer, R., Coulson, I. \& Heath, M. 1997. Foraging behaviour and ecology of the cape pangolin (manis temminckii) in north-western zimbabwe. African Journal of Ecology, 35, 361-369.

Roberts, T. 1997. The mammals of pakistan (revised ed.) oxford university press. Karachi, Pakistan, 525.

Roberts, T. \& Vielliard, J. 1971. Commentaires sur le grand pangolin indien manis crassicaudata. Mammalia, 35, 610-613.

Rowcliffe, J. M., Field, J., Turvey, S. T. \& Carbone, C. 2008. Estimating animal density using camera traps without the need for individual recognition. Journal of Applied Ecology, 45, 1228-1236.

Sanyal, R. B. 1892. A hand-book of the management of animals in captivity in lower bengal, Printed at the Bengal Secretariat Press.

Shek, C.-T., Chan, C. S. \& Wan, Y.-F. 2007. Camera trap survey of hong kong terrestrial mammals in 2002-06. Biodiversity, 15, 1-11.

Swart, J., Richardson, P. \& Ferguson, J. 1999. Ecological factors affecting the feeding behaviour of pangolins (manis temminckii). Journal of Zoology, 247, 281-292.

Weber, M. 1904. Die" objektivität" sozialwissenschaftlicher und sozialpolitischer erkenntnis. Archiv für sozialwissenschaft und sozialpolitik, 19, 22-87.

Weerakoon, D. K. 2012. The taxonomy and conservation status of mammals in sri lanka. The National Red List 2012 of Sri Lanka, Conservation Status of the Fauna and Flora, 138-144.

Wilson, D. E. \& Reeder, D. M. 2005. Mammal species of the world: A taxonomic and geographic reference, JHU Press.

Wilson, G. J. \& Delahay, R. J. 2001. A review of methods to estimate the abundance of terrestrial carnivores using field signs and observation. Wildlife Research, 28, 151-164.

Wu, S., Liu, N., Ma, G., Xu, Z. \& Chen, H. 2003. Habitat selection by chinese pangolin (manis pentadactyla) in winter in dawuling natural reserve. Mammalia, 67, 493-502.

Yadav, R. 1973. Rearing of indian pangolin. Indian Zoo Bulletin 1, 6.

Yang, C. W., Chen, S., Chang, C. Y., Lin, M. F., Block, E., Lorentsen, R., Chin, J. S. \& Dierenfeld, E. S. 2007. History and dietary husbandry of pangolins in captivity. Zoo biology, 26, 223-230.

Zhou, Z.-M., Zhou, Y., Newman, C. \& Macdonald, D. W. 2014. Scaling up pangolin protection in china. Frontiers in Ecology and the Environment, 12, 97-98. 